HECKTHEUER, Pedro Abib; PIGNANELI, Guilherme da Costa Ferreira; HECKTHEUER, Marcia Abib. O E-Commerce como potencializador da insustentável cultura do consumo na sociedade tecnológica: um desafio sociambiental. Revista Eletrônica Direito e Política, Programa de Pós-Graduação Stricto Sensu em Ciência Jurídica da UNIVALI, Itajaí, v.12, n.3, $3^{\circ}$ quadrimestre de 2017. Disponível em: www.univali.br/direitoepolitica - ISSN 1980-7791

\title{
O E-COMMERCE COMO POTENCIALIZADOR DA INSUSTENTÁVEL CULTURA DO CONSUMO NA SOCIEDADE TECNOLÓGICA: UM DESAFIO SOCIAMBIENTAL
}

\author{
E-COMMERCE AS A POTENTIATOR FOR THE UNSUSTAINABLE CULTURE OF \\ CONSUMPTION IN THE TECHNOLOGICAL SOCIETY: A SOCIOENVIRONMENTAL \\ CHALLENGE
}

Pedro Abib Hecktheuer ${ }^{1}$

Guilherme da Costa Ferreira Pignaneli²

Marcia Abib Hecktheuer ${ }^{3}$

SUMÁRIO: Introdução; 1 O consumo como papel central na vida das pessoas; 2 O E-Commerce como potencializador do consumo inconsciente e insustentável; Considerações finais; Referências das fontes citadas

\section{RESUMO}

O presente artigo tem como objetivo compreender se o comércio eletrônico (ecommerce) se apresenta como um potencializador da cultura do consumo na sociedade contemporânea, bem como avaliar a viabilidade dessa formatação social

\footnotetext{
1 Professor de Direito Constitucional da graduação e pós-graduação da Faculdade Católica de Rondônia (FCR), Coordenador do Curso de Direito da Faculdade Católica de Rondônia (FCR). Graduado em Direito pela Faculdade Palotina de Santa Maria, Rio Grande do Sul (FAPAS). Especialista em Direito pela Universidade Gama Filhos (UGF). Mestrando em Direito Econômico e Socioambiental pela Pontifícia Universidade Católica do Paraná (PUCPR). Bolsista junto à Fundação Rondônia de Amparo ao Desenvolvimento das Ações científicas e tecnológicas e à Pesquisa do Estado de Rondônia - FAPERO/CAPES. Advogado. E-mail: pedro_abib@hotmail.com.

2 Professor de Processo Civil na graduação e pós-graduação da Faculdade Católica de Rondônia (FCR). Mestrando em Direito Econômico e Desenvolvimento pela Pontifícia Universidade Católica do Paraná (PUCPR). Especialista em Direito Empresarial pela Fundação Getúlio Vargas (FGV) - LLM em Direito Empresarial - Rio de Janeiro. Graduado em Direito pela Pontifícia Universidade Católica do Paraná (PUCPR). Advogado. E-mail: guilherme@dplaw.com.br

${ }^{3}$ Graduada pela Universidade Católica de Pelotas (UCPEL). Doutora pela Universidade Autônoma de Madrid (UAM) com apostilamento pela Universidade Federal de Santa Maria (UFSM). Professora dos Cursos de Direito e Filosofia e Diretora Acadêmica da Faculdade Católica de Rondônia (FCR). Professora do Programa de Pós-Graduação em Ciência Política da Universidade Federal do Rio Grande do Sul (UFRGS). E-mail: marcia.abib@gmail.com.
} 
HECKTHEUER, Pedro Abib; PIGNANELI, Guilherme da Costa Ferreira; HECKTHEUER, Marcia Abib. O E-Commerce como potencializador da insustentável cultura do consumo na sociedade tecnológica: um desafio sociambiental. Revista Eletrônica Direito e Política, Programa de Pós-Graduação Stricto Sensu em Ciência Jurídica da UNIVALI, Itajaí, v.12, n.3, $3^{\circ}$ quadrimestre de 2017. Disponível em: www.univali.br/direitoepolitica - ISSN 1980-7791

sob o aspecto socioambiental, por meio do método bibliográfico-dedutivo, para o fim de conseguir compreender os reais efeitos da convergência da tecnologia e da informação na sociedade pós-moderna. Para tanto, foram analisados os pontos de ligação entre as sociedades de consumo e a informacional (tecnológica), da mesma forma, abordou-se o surgimento dessa ideia de cultura do consumo, para posteriormente apresentar o comércio eletrônico e as suas formas de potencializar a cultura do consumo, por meio de um modelo de marketing diferenciado, que estimula o consumismo. Por fim, compreendeu-se sobre a insustentabilidade socioambiental desse modelo social e a necessidade de conscientização sobre o consumo, carecendo de uma participação Estatal nessa educação para o consumo consciente como forma de viabilizar a compatibilidade das futuras gerações na terra.

PALAVRAS-CHAVE: E-commerce; cultura do consumo; sociedade de consumo; sociedade tecnológica; socioambiental; insustentabilidade.

\section{ABSTRACT}

The purpose of this article is to understand if electronic commerce (e-commerce) presents itself as a potentiator of consumer culture in contemporary society, as well as evaluate the viability of this social format under the socioenvironmental aspect, through the bibliographic-deductive method, in order to understand the real effects of the convergence of technology and information in postmodern society. Therefore, we analyzed the points of connection between consumer societies and informational (technological), in the same way we approached the emergence of this idea of consumption culture, to later present e-commerce and its ways of strengthening the culture of consumption, through a differentiated marketing model that stimulates consumerism. Finally, it was understood about the socioenvironmental unsustainability of this social model and the need for awareness about consumption, understanding that is necessary a state participation in this education for conscious consumption as a way to make the compatibility of future generations on earth.

KEYWORDS: E-commerce; consumer culture; consumer society; technological society; socioenvironmental; unsustainability.

\section{INTRODUÇÃO}

O consumo na sociedade contemporânea passou a ter papel central na vida das pessoas, deixando de ser uma atividade individual ligada a satisfação das necessidades básicas para se tornar um ato público, disseminado e compartilhado, marcado pela abundância de mercadorias, pelo culto extremo dos objetos, pela reciclagem de vontade, bem como pela obsolescência dos produtos. 
HECKTHEUER, Pedro Abib; PIGNANELI, Guilherme da Costa Ferreira; HECKTHEUER, Marcia Abib. O E-Commerce como potencializador da insustentável cultura do consumo na sociedade tecnológica: um desafio sociambiental. Revista Eletrônica Direito e Política, Programa de Pós-Graduação Stricto Sensu em Ciência Jurídica da UNIVALI, Itajaí, v.12, n.3, $3^{\circ}$ quadrimestre de 2017. Disponível em: www.univali.br/direitoepolitica - ISSN 1980-7791

Fato é que a forma como o ser humano interage em sociedade tende a ditar as regras do jogo e, portanto, na atualidade, essas são estabelecidas pela lei do consumo. Logo, para atender a todos esses anseios, bens são produzidos de forma massificada, retroalimentando esse círculo vicioso alicerceado pelo dilema de causalidade: se produz porque se consome ou se consome porque se produz.

Independentemente do que está por detrás desse fenômeno intitulado de sociedade de consumo, o certo é que a cada dia essas relações se tornam cada vez mais complexas e dinâmicas a ponto de impactar diretamente na economia, na política, no judiciário e no meio ambiente.

Apesar de o consumo haver estado, sempre, presente nas sociedades anteriores, no entanto agora, demos espaço a uma cultura de consumismo, que se potencializou com o advento das novas tecnologias, conduzindo a um problema de pesquisa no sentido de buscar resposta ao questionamento de se estaria o ecommerce sendo um potencializador da cultura do consumo na sociedade tecnológica bem como se seria viável esse modelo social.

Intuía-se que o advento da internet, bem como a facilidade com que a informação passou a circular entre as pessoas, com ênfase no e-commerce, potencializou a cultura do consumo, e de um consumo insustentável, vez que a matéria prima é finita para esse que é o papel central desta sociedade, o consumo, que provém de um meio ambiente não renovável.

O presente estudo abordará a partir do método bibliográfico-dedutivo os efeitos da convergência da tecnologia e da informação na sociedade pós-moderna, especialmente no fator e-commerce como potencializador da insustentabilidade da sociedade de consumo.

Para tanto, abordar-se-ão conceitos operacionais sobre a sociedade de consumo com as motivações históricas que a deram origem, bem como a progressão para chegarmos àquelas denominadas de tecnológica ou da informação. 
HECKTHEUER, Pedro Abib; PIGNANELI, Guilherme da Costa Ferreira; HECKTHEUER, Marcia Abib. O E-Commerce como potencializador da insustentável cultura do consumo na sociedade tecnológica: um desafio sociambiental. Revista Eletrônica Direito e Política, Programa de Pós-Graduação Stricto Sensu em Ciência Jurídica da UNIVALI, Itajaí, v.12, n.3, $3^{\circ}$ quadrimestre de 2017. Disponível em: www.univali.br/direitoepolitica - ISSN 1980-7791

Na sequência se abordarão as inovações tecnológicas que proporcionaram o comercio eletrônico, também chamado de e-commerce, que com a internet representou uma verdadeira disseminação do consumo, passando, ao final, por uma discussão sobre a insustentabilidade desse consumismo, que foi potencializado com essa ferramenta.

\section{CONSUMO COMO PAPEL CENTRAL NA VIDA DAS PESSOAS}

Sociedade de risco ${ }^{4}$, líquidaa ${ }^{5}$, da informação ${ }^{6}$, informacional ${ }^{7}$ e de consumo, são apenas algumas das inúmeras classificações que tentam definir e conceituar a sociedade contemporânea. Quanto à última, é certo que o consumo não é uma atividade exclusiva da nossa sociedade, pelo contrário, sempre esteve presente em toda e qualquer sociedade humana.

Então, por qual motivo respectivo substantivo ganha importância na sociedade atual a ponto de rotula-la? Essa sociedade possui algum tipo específico de consumo que a diferencia das anteriores? Essa sociedade possui características sociais particulares?

Barbosa $^{8}$, quando afrontada com as questões acima apresenta a possibilidade de se responder positivamente a ambas, no sentido de que determinados autores compreendem que tanto é a sociedade que possui a especificidade de um consumo de signo (commodity sign) como, por outro lado, há aqueles que entendem que se refere a questões sociológicas para além do commodity sign, como consumo de massas e para as massas, alta taxa de consumo e de descarte de mercadorias per

\footnotetext{
${ }^{4}$ Ver mais em BECK, Ulrich. A Critical Introduction to the Risk Society. London: Pluto Press, 2004.

${ }^{5}$ Ver mais em BAUMAN, Zygmunt. Modernidade Liquida. Rio de Janeiro: Editora Zahar, 2001.

${ }^{6}$ Ver mais em MACHLUP, Fritz. The Production and Distribution of Knowledge in the United States. Review of Economic Studies, 1935.

7 Ver mais em: CASTELLS, Manuel. A Galáxia Internet: reflexões sobre a Internet, negócios e a sociedade. Zahar, 2003.
}

${ }^{8}$ BARBOSA, Lívia. Sociedade de Consumo. Rio de Janeiro: Jorge Zahar Editora, 2004, p. 8. 
HECKTHEUER, Pedro Abib; PIGNANELI, Guilherme da Costa Ferreira; HECKTHEUER, Marcia Abib. O E-Commerce como potencializador da insustentável cultura do consumo na sociedade tecnológica: um desafio sociambiental. Revista Eletrônica Direito e Política, Programa de Pós-Graduação Stricto Sensu em Ciência Jurídica da UNIVALI, Itajaí, v.12, n.3, $3^{\circ}$ quadrimestre de 2017. Disponível em: www.univali.br/direitoepolitica - ISSN 1980-7791

capita, presença da moda, sociedade de mercado, sentimento permanente de insaciabilidade e o consumidor como um de seus principais personagens sociais".

No commodity sign, a mercadoria se afasta da sua utilidade para dar lugar a um meio de expressão, uma identidade. O consumo de signo é facilmente entendido pela frase, uma vez dita por Irving Penn ${ }^{9}$, fotografo da revista Vogue, e mundialmente propagada, quando ele fazendo menção ao seu trabalho, lucidamente, pontou que sua função era de "vender sonhos, não roupas".

Nas palavras de Svendsen ${ }^{10}$, o consumo de signo, "se desconectou em alto grau do que podemos razoavelmente chamar de satisfação de necessidades". Nessa sociedade, portanto, o ato de consumir também pode ser considerado uma ferramenta de distração, ou seja, de entretenimento.

Mas, como visto, o tema transcende o consumo de signos, porquanto existem outros fatores que também estão presentes nesse tipo de sociedade, tais quais a elevação do nível da vida, abundância das mercadorias e dos serviços, culto dos objetos e dos lazeres, moral hedonista e materialista ${ }^{11}$.

Para Bauman ${ }^{12}$, o que a difere esta sociedade das anteriores é o papel central que o consumo ganha na vida das pessoas, o consumo, sempre presente nas sociedades anteriores, dá espaço para o consumismo. Nesse momento, deixa de ser uma atividade individual e passa a ser social ao passo que promove, encoraja e reforça a escolha de um estilo de vida e uma estratégia existencial consumista e rejeita as demais opções culturais alternativas.

\footnotetext{
9 SVENDSEN, Lars. Moda: uma filosofia. Tradução: Maria Luiza X. de A. Borges. Rio de Janeiro : Zahar, 2010, p. 131.

10 SVENDSEN, Lars. Moda: uma filosofia. Tradução: Maria Luiza X. de A. Borges. Rio de Janeiro : Zahar, 2010, p. 154

11 LIPOVETSKY, Gilles. O império do efêmero: a moda e seu destino nas sociedades modernas. Tradução: Maria Lucia Machado. São Paulo: Companhia das Letras, 2009.

12 BAUMAN, Zygmunt. Vida para o consumo. Rio de Janeiro: Editora Zahar, 2008.
} 
HECKTHEUER, Pedro Abib; PIGNANELI, Guilherme da Costa Ferreira; HECKTHEUER, Marcia Abib. O E-Commerce como potencializador da insustentável cultura do consumo na sociedade tecnológica: um desafio sociambiental. Revista Eletrônica Direito e Política, Programa de Pós-Graduação Stricto Sensu em Ciência Jurídica da UNIVALI, Itajaí, v.12, n.3, $3^{\circ}$ quadrimestre de 2017. Disponível em: www.univali.br/direitoepolitica - ISSN 1980-7791

O que se vê, portanto, é que o conceito de sociedade de consumo carece de uma definição única e perfeita podendo ganhar contornos diferentes dependendo da abordagem do interlocutor e, além das diferentes abordagens citadas, o tema ganha ainda mais complexidade uma vez que é facilmente confundido e tratado como sinônimo de cultura de consumo.

Enquanto o viés da cultura apresenta uma relação íntima e causal entre o consumo e o estilo de vida, reprodução social e identidade, ou seja, a estetização, o signo como mercadoria, materialismo e superficialidade, entre outros, a sociedade de consumo, por sua vez, faz toda uma outra análise por meio de questionamentos que buscam relacionar os porquês de as pessoas consumirem determinados tipos de bens, em determinadas circunstâncias e maneiras, em síntese, faz uma análise de como o consumo se inter-relaciona com outras esferas da experiência humana e até que ponto serve como um modelo de interpretação dos processos sociais e culturais $^{13}$.

Os autores que discutem o consumo sob o prisma cultural o fazem muito mais como uma ciência descritiva e poucas vezes enfrentam o tema de forma crítica. Essa visão parte de uma "postura teórica universalizante sobre o significado e o papel do consumo na vida cotidiana das pessoas, que não distingue tipos de consumo, grupos sociais e os múltiplos significados da atividade de consumir"14 e ainda acrescenta Bauman ${ }^{15}$ que:

Si la cultura consumista es la forma en que los miembros de una sociedad de consumidores actúan "irreflexivamente" en otras palabras, sin pensar en aquello que consideran el propósito de sus vidas y en los medios más adecuados para alcanzarlo, sin pensar en lo que os distinguen todo aquello que es relevante para ese propósito de aquello que descartan por irrelevante, sin pensar en lo que los entusiasma y en lo que les resulta indiferente $o$ desabrido, en lo que los atrae y en lo que los repele, en lo que los empuja a actuar y en lo que los llama a la fuga, en lo que desean

\footnotetext{
13 BARBOSA, Lívia. Sociedade de Consumo. Rio de Janeiro: Jorge Zahar Editora, 2004.

${ }^{14}$ BARBOSA, Lívia. Sociedade de Consumo. Rio de Janeiro: Jorge Zahar Editora, 2004, p. 11.

15 BAUMAN, Zygmunt. Vida para o consumo. Traducción de Mirta Rosenberg y Jaime. Arramrlde. Madrid: Fundo de Cultura Econômica, 2012, p. 77.
} 
HECKTHEUER, Pedro Abib; PIGNANELI, Guilherme da Costa Ferreira; HECKTHEUER, Marcia Abib. O E-Commerce como potencializador da insustentável cultura do consumo na sociedade tecnológica: um desafio sociambiental. Revista Eletrônica Direito e Política, Programa de Pós-Graduação Stricto Sensu em Ciência Jurídica da UNIVALI, Itajaí, v.12, n.3, $3^{\circ}$ quadrimestre de 2017. Disponível em: www.univali.br/direitoepolitica - ISSN 1980-7791

y en lo que temen, sin pensar hasta qué punto temores y deseos se compensan unos a otros - , entonces la sociedad de consumidores (o de consumo) refiere a un conjunto específico de condiciones de existencia bajo las cuales son muy altas las probabilidades de que la mayoría de los hombres y mujeres adopten el consumismo antes que cualquier otra cultura, así como las de que casi siempre hagan todo lo posible por obedecer sus preceptos.

Extrai-se da leitura de Bauman, bem como do que já fora supramencionado que a sociedade de consumo é decorrente de uma série de circunstâncias históricas, é um processo, da qual um dos pilares é a cultura de massa, de consumo.

Essa cultura faz a transformação da ideia do "simples trabalhador transformado em trabalhador-consumidor, da obra de arte transformada em mercadoria; enfim, da cultura transformada em produto"16.

Por outro lado, os que analisam sob a perspectiva social, ultrapassam essa característica supérflua e ostentatória do ato de consumir. Para eles, "isto significa admitir que o consumo está preenchendo, entre nós, uma função acima e além daquela de satisfação de necessidades materiais e de reprodução social comum a todos os demais grupos sociais" ${ }^{\prime 17}$.

Depois desta contextualização, resta esclarecer em que momento se deu essa migração para a sociedade de consumo, vez que o ato de consumir, mesmo que de forma incipiente, é traço característico de todas as sociedades, desde as mais remotas.

Para tanto, a melhor resposta passa, em verdade, pela reformulação do questionamento, ou seja, pela compreensão de quais foram as mudanças sociais que causaram essa migração, isso porque, como toda transformação social, não

\footnotetext{
16 GONÇALVES, Sérgio Campos. Cultura e Sociedade de Consumo: um olhar em retrospecto. InRevista - Nucleo de Produção Cientifica em Comunicação-UNAERP, Ribeirão Preto, v. 5, 2008 , p.
} 23.

17 BARBOSA, Lívia. Sociedade de Consumo. Rio de Janeiro: Jorge Zahar Editora, 2004, p. 14. 
HECKTHEUER, Pedro Abib; PIGNANELI, Guilherme da Costa Ferreira; HECKTHEUER, Marcia Abib. O E-Commerce como potencializador da insustentável cultura do consumo na sociedade tecnológica: um desafio sociambiental. Revista Eletrônica Direito e Política, Programa de Pós-Graduação Stricto Sensu em Ciência Jurídica da UNIVALI, Itajaí, v.12, n.3, $3^{\circ}$ quadrimestre de 2017. Disponível em: www.univali.br/direitoepolitica - ISSN 1980-7791

há um momento exato para o seu acontecimento, mas sim, a convergência de inúmeros fatores e acontecimentos históricos.

O certo é que, a partir do século XVI, registra-se o lançamento de um conjunto de novos bens de consumo, formado em boa parte por produtos supérfluos, nas sociedades ocidentais em razão da sua expansão marítima.

Além disso, a opulência econômica vivenciada por aquela sociedade afetou, diretamente, sua dimensão cultural, trazendo, consigo, a preocupação com novas formas de lazer, a expansão da ideologia, bem como o aumento da literalidade da população. Com isso, houve a mudança do consumo familiar para o individual e a alteração do consumo de prática para o de moda ${ }^{18}$. Segundo Bauman ${ }^{19}$, o consumismo pode ser entendido como:

\begin{abstract}
Um tipo de arranjo social resultante da reciclagem de vontades, desejos e anseios humanos rotineiros, permanentes e, por assim dizer, "neutros quanto ao regime", transformando-os na principal força propulsora e operativa da sociedade, uma força que coordena a reprodução sistêmica, a integração e a estratificação sociais, além da formação de indivíduos humanos, desempenhando ao mesmo tempo um papel importante nos processos de auto-identificação individual e de grupo, assim como na seleção e execução de políticas de vida individuais.
\end{abstract}

Portanto, se pode dizer que lentamente o consumismo foi ganhando espaço na vida da das pessoas. A guinada se dá no sentido de que o consumo não ocorre a partir de escolhas, de preferências pessoais, mas em uma dimensão pública, oriundo de deliberações coletivas, até se consolidar como papel-chave na vida das pessoas, ou seja, o verdadeiro propósito de existir ${ }^{20}$.

Outros autores preferem trabalhar a sociedade contemporânea sob o viés da informação, "uma sociedade que seria cada vez mais caracterizada pela

18 BARBOSA, Lívia. Sociedade de Consumo. Rio de Janeiro: Jorge Zahar Editora, 2004.

19 BAUMAN, Zygmunt. Vida para o consumo. Rio de Janeiro: Editora Zahar, 2008, p. 41.

20 JENKINS, Henry. Convergence culture: Where old and new media collide. NYU press, 2006, p. 222. 
HECKTHEUER, Pedro Abib; PIGNANELI, Guilherme da Costa Ferreira; HECKTHEUER, Marcia Abib. O E-Commerce como potencializador da insustentável cultura do consumo na sociedade tecnológica: um desafio sociambiental. Revista Eletrônica Direito e Política, Programa de Pós-Graduação Stricto Sensu em Ciência Jurídica da UNIVALI, Itajaí, v.12, n.3, $3^{\circ}$ quadrimestre de 2017. Disponível em: www.univali.br/direitoepolitica - ISSN 1980-7791

informação, pela comunicação, pelo saber e pelo conhecimento. Mas também, e sobretudo, pelos dispositivos técnicos capazes de veicular tais informações, saberes e conhecimentos" 21 .

Esse olhar passou a ser dado em meados da década de 60, em virtude do desenvolvimento de tecnologias de informação e comunicação (TIC), fazendo com que a sociedade passasse a se organizar em torno da informação 22 (FREITA, 2015, p.77).

Dessa forma, enquanto, por um lado, a sociedade de consumo coloca o consumismo como objeto da sua ciência, a sociedade da informação, como o próprio nome indica, foca nesse processo de transmissão de informações, por meio da comunicação, tornando um ciclo pelo qual se gera ainda mais informação, dando acesso a mais e mais pessoas, em diferentes e distantes lugares ${ }^{23}$.

Denota-se que na mesma medida que a sociedade de consumo não foi responsável pela criação do ato de consumir, a sociedade da informação também não foi pela comunicação. Em verdade, ambas as sociedades ganham status a partir do momento que reinventam, cada uma a seu modo e tempo, uma ação presente em toda a sociedade, seja o consumo, seja a comunicação.

E, dentro desse cenário, identifica-se como mola propulsora da sociedade da informação, justamente, a tecnologia. O avanço tecnológico desfrutado na história mais recente permitiu desde o surgimento do rádio, da televisão, da telefonia fixa e móvel até o seu grande apogeu, a internet, a potencialização do acesso e compartilhamento de informações.

21 GEROGE, Eric, Da "sociedade da informação" à "sociedade 2.0": o retorno dos discursos "míticos" sobre o papel das TICs nas sociedades. Líbero - São Paulo - v. 14, n. 27, p. 45-54, jun. de 2011, p. 46.

22 FREITAS, C. O. A. A Vulnerabilidade do Consumidor e a Exposição Pública na Internet. In: Aires José Rover, Fernando Galindo. (Org.). III Encontro de Internacionalização do CONPEDI / Universidad Complutense de Madrid. 1ed.Madrid: Ediciones Laborum, 2015, p. 77.

${ }^{23}$ FREITAS, C. O. A. A Vulnerabilidade do Consumidor e a Exposição Pública na Internet. In: Aires José Rover, Fernando Galindo, 2015, p. 78. 
HECKTHEUER, Pedro Abib; PIGNANELI, Guilherme da Costa Ferreira; HECKTHEUER, Marcia Abib. O E-Commerce como potencializador da insustentável cultura do consumo na sociedade tecnológica: um desafio sociambiental. Revista Eletrônica Direito e Política, Programa de Pós-Graduação Stricto Sensu em Ciência Jurídica da UNIVALI, Itajaí, v.12, n.3, $3^{\circ}$ quadrimestre de 2017. Disponível em: www.univali.br/direitoepolitica - ISSN 1980-7791

Dentro desse contexto, o que se vê, na prática, é que a sociedade de consumo e a sociedade da informação (tecnologia) são duas faces da mesma moeda. Isso porque, as mídias veiculadoras de informação, são as mesmas que retroalimentam esse ciclo vicioso do desejo pelo novo.

Nascimento ${ }^{24}$ acrescenta um fator importante ao dizer que "a mídia influencia o consumo e administra o efêmero através das propagandas e das imagens em geral, como as de publicações de moda, programas de televisão e filmes", sendo a internet, portanto, o terreno mais fértil para a proliferação dessa sociedade. Ou seja, a ação midiática faz com que as fantasias e mercadorias sejam efêmeras e que tenhamos consumidores nunca satisfeitos.

$\mathrm{Na}$ concepção do mesmo autor, o que caracteriza a revolução tecnológica atual não é o caráter central do conhecimento e da informação, mas a aplicação deste conhecimento e informação a aparatos de geração de conhecimento e processamento da informação/comunicação, em um círculo de retroalimentação acumulativa entre a inovação e seus usos.

Nesse sentido, a difusão da tecnologia amplifica infinitamente seu poder ao se apropriar de seus usuários e redefini-los. As novas tecnologias da informação não são apenas ferramentas para se aplicar, mas processos para se desenvolver. Nesse passo, pela primeira vez na história, a mente humana é uma força produtiva direta, não apenas um elemento decisivo do sistema de produção ${ }^{25}$.

A partir da revolução tecnológica, concentrada nas Tecnologias de Informação e Comunicação, passa-se por uma reformulação de toda a sociedade, e no centro desta revolução estão os computadores/mobiles conectados à Internet.

A internet nasceu com objetivos diversos daqueles ao que hoje se propõe, por meio de um projeto militar americano no período da Guerra Fria, entre os anos 50

\footnotetext{
24 NASCIMENTO. Marina Correa de Sá, A moda de o grande gatsby: uma análise do consumo na pósmodernidade. Trabalho apresentado à Faculdade de Tecnologia e Ciências Sociais Aplicadas, 2013 , p. 32.
}

25 CASTELLS, Manuel. A Galáxia Internet: reflexões sobre a Internet, negócios e a sociedade. Zahar, 2003. 
HECKTHEUER, Pedro Abib; PIGNANELI, Guilherme da Costa Ferreira; HECKTHEUER, Marcia Abib. O E-Commerce como potencializador da insustentável cultura do consumo na sociedade tecnológica: um desafio sociambiental. Revista Eletrônica Direito e Política, Programa de Pós-Graduação Stricto Sensu em Ciência Jurídica da UNIVALI, Itajaí, v.12, n.3, $3^{\circ}$ quadrimestre de 2017. Disponível em: www.univali.br/direitoepolitica - ISSN 1980-7791

e 60 do século passado, com a ideia embrionária de conectar os centros universitários com o Pentágono, a fim de transmitir informação de forma rápida, precisa e segura ${ }^{26}$.

O projeto foi concebido originalmente com o nome de Advanced Research Projects Agency (ARPA) para propósitos militares. Já, no início dos anos 70, a Arpanet, como ficou popularmente conhecida, conectava 15 centros universitários e expandia a sua utilização para fins acadêmicos. Entretanto, foi apenas no início da década de 90 daquele século, que o sistema chegou às casas das pessoas, para se tornar, a partir daí, na maior transformação cultural, social e econômica da história recente ${ }^{27}$.

O fato é que a internet interliga dezena de milhões de computadores em todo o mundo, dando acesso irrestrito às informações ${ }^{28}$, ou seja, "a internet é uma rede internacional ou de computadores interconectados, que permite que se comuniquem entre si dezenas de milhões de pessoas, bem como o acesso a uma imensa quantidade de informações de todo mundo"29.

Se a sociedade de consumo ficou popularmente conhecida pelo consumo em massa, com o advento da internet esse consumo se intensificou ainda mais, sendo classificado por alguns pesquisadores como "pós-massiva". Para essa corrente, as relações comerciais que com os antigos meios de comunicação (jornal, rádio e

${ }^{26}$ FREITAS, C. O. A. A Vulnerabilidade do Consumidor e a Exposição Pública na Internet, p. 77.

27 FREITAS, C. O. A. A Vulnerabilidade do Consumidor e a Exposição Pública na Internet, p. 77.

28 PAESANI, Liliana Minardi. Direito e Internet Liberdade de Informação, Privacidade e Responsabilidade Civil. $5 .^{\circ}$ ed: São Paulo: Atlas, 2012, p. 10-11.

29 LORENZETTI, Ricardo Luis, Comércio Eletrônico: Tradução de Fabiano Menk; com notas de Cláudia Lima Marques. São Paulo: Revistas dos Tribunais, 2004, p. 24. 
HECKTHEUER, Pedro Abib; PIGNANELI, Guilherme da Costa Ferreira; HECKTHEUER, Marcia Abib. O E-Commerce como potencializador da insustentável cultura do consumo na sociedade tecnológica: um desafio sociambiental. Revista Eletrônica Direito e Política, Programa de Pós-Graduação Stricto Sensu em Ciência Jurídica da UNIVALI, Itajaí, v.12, n.3, $3^{\circ}$ quadrimestre de 2017. Disponível em: www.univali.br/direitoepolitica - ISSN 1980-7791

televisão) eram realizadas na forma um-para-todos (massiva), se transformaram, com a popularização da internet, em relações todos-para-todos (pós-massiva) ${ }^{30,31}$.

Como se percebe pelas explicações até aqui expostas, a sociedade de consumo, que teve como estopim a expansão marítima ocidental, vem evoluindo e se reinventando de tempos em tempos, sendo que uma dessas evoluções passa justamente no advento da internet (tecnologia) e a facilidade com que a informação (sociedade da informação) passou a circular entre as pessoas até resultar no comércio eletrônico (e-commerce).

\section{O E-COMMERCE COMO POTENCIALIZADOR DO CONSUMO INCONSCIENTE E INSUSTENTÁVEL}

O comércio eletrônico, também chamado de e-commerce, representa toda e qualquer transação comercial realizada na rede mundial de computadores, fato que se proporcionou pela facilidade com que se passou a ter de acesso à internet, momento em que o comércio tradicional passou a utilizar os meios tecnológicos, além disso, "a diminuição de custos e a celeridade foram fatores decisivos na concretização dos negócios jurídicos pela Internet"32.

Em outras palavras, o comércio eletrônico é "a realização de toda a cadeia de valor dos processos de negócios num ambiente eletrônico, por meio da aplicação intensa das tecnologias de comunicação e informação, atendendo aos objetivos do negócio" ${ }^{\prime 3}$.

\footnotetext{
30 LEMOS, André. e Lévy, Pierre, O Futuro da internet: em direção a uma ciberdemocracia. São Paulo: Paulus, 2010.

${ }^{31}$ CORREA, Fabiano Simoes. Um estudo sobre as representações utilizadas por professores e alunos para significar o uso da internet. Dissertação de Mestrado apresentada à Faculdade de Filosofia, Ciencias e Letras de Ribeirão Preto da USP, 2013.

32 FIGUEIREDO, Márcio, FIGUEIREDO, Cristiane e MOREIRA, Halbert. Comércio eletrônico e o direito do consumidor no Brasil, 2015, p. 4.
}

33 ALBERTIN, Alberto L. Comércio eletro^ nico: modelo, aspectos e contribuições de sua aplicação. São Paulo: ATLAS, 2002, p15. 
HECKTHEUER, Pedro Abib; PIGNANELI, Guilherme da Costa Ferreira; HECKTHEUER, Marcia Abib. O E-Commerce como potencializador da insustentável cultura do consumo na sociedade tecnológica: um desafio sociambiental. Revista Eletrônica Direito e Política, Programa de Pós-Graduação Stricto Sensu em Ciência Jurídica da UNIVALI, Itajaí, v.12, n.3, $3^{\circ}$ quadrimestre de 2017. Disponível em: www.univali.br/direitoepolitica - ISSN 1980-7791

Com isso, mudou por completo o meio de acesso aos produtos e a forma pela qual se concretiza essa relação, acentuado recentemente por meio das redes sociais, principalmente com a difusão dos smartphones e tablets, momento em que se deflagrou mudanças comportamentais, sociais e econômicas nunca antes verificadas ${ }^{34}$.

Em que pese a essência da relação permanecer a mesma há séculos, comércio e consumo, a forma com que essas duas ações são realizadas são totalmente reformuladas na sociedade contemporânea (sociedade de informação e de consumo), de forma que, agora, a relação comercial se dá de inúmeras formas (Tabela 2), tendo em conta o carácter dos participantes, tais como: empresa para empresa; empresa para o consumidor; consumidor para o consumidor; governo para o cidadão; e, por fim, governo e empresas.

\section{Tabela 2}

\begin{tabular}{|c|c|c|c|}
\hline \multicolumn{4}{|c|}{ E-commerce e aplicativos de Internet mais amplos } \\
\hline & Government & Business & Consumer \\
\hline Government & $\begin{array}{c}\text { G2G } \\
\text { ex: coordenação }\end{array}$ & $\begin{array}{c}\text { G2B } \\
\text { ex.: informação }\end{array}$ & $\begin{array}{c}\text { G2C } \\
\text { ex.: informação }\end{array}$ \\
\hline Business & $\begin{array}{c}\text { B2G } \\
\text { ex.: aquisição }\end{array}$ & $\begin{array}{c}\mathrm{B} 2 \mathrm{~B} \\
\text { ex.: e-commerce }\end{array}$ & $\begin{array}{c}\mathrm{B} 2 \mathrm{C} \\
\text { ex.: e-commerce }\end{array}$ \\
\hline Consumer & $\begin{array}{c}\text { C2G } \\
\text { ex.: cumprimento } \\
\text { de obrigações } \\
\text { fiscais }\end{array}$ & $\begin{array}{c}\text { C2B } \\
\text { ex.: comparação } \\
\text { de preços }\end{array}$ & $\begin{array}{c}\mathrm{C} 2 \mathrm{C} \\
\text { ex.: leilões }\end{array}$ \\
\hline
\end{tabular}

Fonte: Coppel ${ }^{35}$

Além disso, podem ser classificadas de acordo com a plataforma utilizada: mcommerce (mobile-commerce), s-commerce (social-commerce), t-commerce (TV-

${ }^{34}$ FREITAS, C. O. A.. A Vulnerabilidade do Consumidor e a Exposição Pública na Internet, p. $72-82$.

35 COPPEL, Jonathan. E-Commerce: Impacts and Policy Challenges. OECD Economics Department Working Papers. No. 252, Junho de 2000. 
HECKTHEUER, Pedro Abib; PIGNANELI, Guilherme da Costa Ferreira; HECKTHEUER, Marcia Abib. O E-Commerce como potencializador da insustentável cultura do consumo na sociedade tecnológica: um desafio sociambiental. Revista Eletrônica Direito e Política, Programa de Pós-Graduação Stricto Sensu em Ciência Jurídica da UNIVALI, Itajaí, v.12, n.3, $3^{\circ}$ quadrimestre de 2017. Disponível em: www.univali.br/direitoepolitica - ISSN 1980-7791

commerce) e f-commerce (Facebook-commerce), ou seja, o denominado m-s-t-fcommerce ${ }^{36}$.

Para compreender a importância dessa ferramenta na atualidade, de acordo com o relatório Webshoppers (2017), no ano de 2016, o e-commerce faturou no Brasil $\mathrm{R} \$ 44,4$ bilhões, crescimento nominal de $7,4 \%$, sendo que 48 milhões de consumidores compraram no comércio eletrônico pelo menos uma vez no ano, o que representou uma alta de $22 \%$ ante 2015 , sendo que a previsão para o ano de 2017 é de crescimento de $12 \%$, com quase $\mathrm{R} \$ 50$ bi de faturamento (Gráfico 1 ).

\section{GRÁFICO 1 \\ Evolução de faturamento do e-commerce no Brasil (venda de bens de consumo em bilhões de reais)}

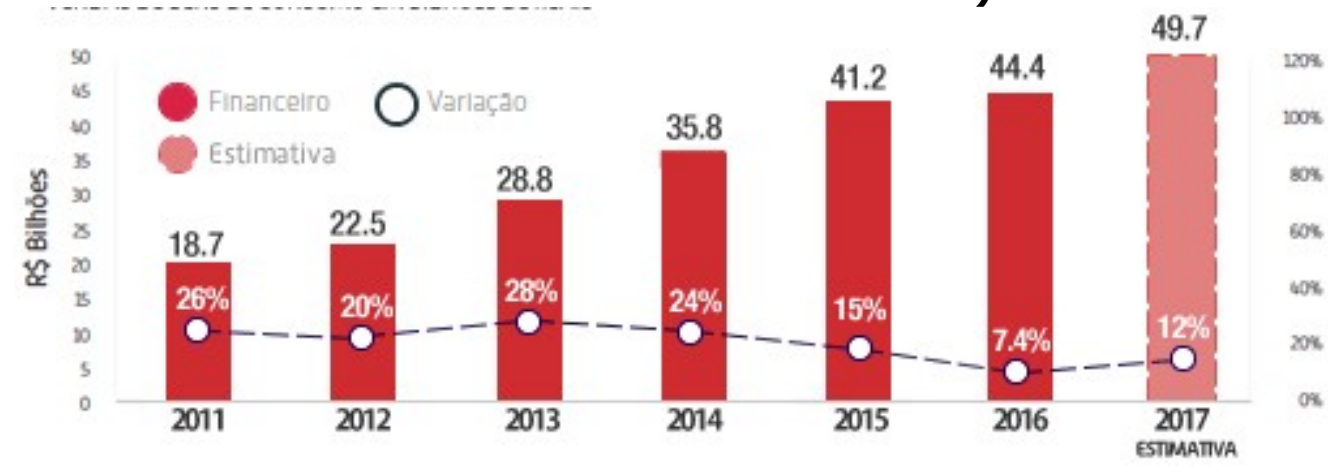

Fonte: Ebit informação (2017)

Pela análise das informações acima se percebe que a popularização do acesso à internet por meio de dispositivos móveis permitiu o rápido acesso às informações de preços, isso, juntamente com a melhora na qualidade dos serviços e experiência de compra, contribuíram para aumentar, por um lado, a migração das compras do consumidor brasileiro para o comércio eletrônico, e por outro, estimular a compra de produtos que, não fosse o e-commerce, provavelmente não seriam consumidos.

Em 2016, registrou-se crescimento no número de e-consumidores ativos no Brasil, mostrando que o consumidor continua buscando encontrar no e-commerce

${ }^{36}$ FREITAS, C. O. A. A Vulnerabilidade do Consumidor e a Exposição Pública na Internet, p. 82. 
HECKTHEUER, Pedro Abib; PIGNANELI, Guilherme da Costa Ferreira; HECKTHEUER, Marcia Abib. O E-Commerce como potencializador da insustentável cultura do consumo na sociedade tecnológica: um desafio sociambiental. Revista Eletrônica Direito e Política, Programa de Pós-Graduação Stricto Sensu em Ciência Jurídica da UNIVALI, Itajaí, v.12, n.3, $3^{\circ}$ quadrimestre de 2017. Disponível em: www.univali.br/direitoepolitica - ISSN 1980-7791

vantagens que o varejo tradicional não consegue oferecer, quais sejam, custo baixo, comodidade, possibilidade de comparar os preços etc.

Vários são os fatores para o incremento do consumo, podem-se citar alguns deles, tais como a globalização, a internet, o desenvolvimento do e-commerce, que se proporcionou pelo surgimento das novas tecnologias, tudo isso facilitou que essa cultura do consumo se acentuasse ${ }^{37}$, podendo-se dar uma ênfase ao marketing de afiliados, modelo por meio do qual as empresas conseguem propagar seus produtos com grande capilaridade na internet, nos mais diversos sites, portais e nas redes sociais ${ }^{38}$.

Como visto, a sociedade de consumo cria desejos perpétuos e intangíveis, uma vez que estão em constante renovação e sempre aos olhos daquele que navega na internet, de tal sorte que "o consumidor pós-moderno projeta um gozo idealizado sobre produtos cada vez mais novos, uma vez que os velhos e bem conhecidos perdem pouco a pouco sua capacidade de encantar"39.

Em que pese todas as benesses do comércio eletrônico aqui aventadas, esse fenômeno precisa ser estudado com cautela, porquanto, ao facilitar e garantir mais segurança ao consumidor, potencializa, ainda mais, o ciclo vicioso do consumo. Ou seja, se de um lado a tecnologia e a informação trabalham de mãos dadas com a sociedade de consumo, do outro, não são utilizadas como ferramentas de reflexão das consequências negativas advindas desse novo modelo social.

Nesse sentido, é necessário destacar que enquanto o consumismo for a base central da vida das pessoas, tanto a tecnologia quanto a informação atenderão as regras do jogo criadas pela sociedade de consumo, logo, a grande questão a ser

37 GONÇALVES, Alex Silva; SCHMIDT, João Pedro. Impactos do consumismo: ação estatal e participação comunitária. Seminário Nacional Demandas Sociais e Políticas Públicas na Sociedade Contemporânea, 2015, p. 7.

38 SMITH, Rob, SPEAKER, Mark. O Mais Completo Guia Sobre E-COMMERCE. Tradução Bazán Tecnologia e Lingüística. São Paulo: Futura, 2000.

39 SVENDSEN, Lars. Moda: uma filosofia. Tradução: Maria Luiza X. de A. Borges. Rio de Janeiro : Zahar, 2010, p. 131. 
HECKTHEUER, Pedro Abib; PIGNANELI, Guilherme da Costa Ferreira; HECKTHEUER, Marcia Abib. O E-Commerce como potencializador da insustentável cultura do consumo na sociedade tecnológica: um desafio sociambiental. Revista Eletrônica Direito e Política, Programa de Pós-Graduação Stricto Sensu em Ciência Jurídica da UNIVALI, Itajaí, v.12, n.3, $3^{\circ}$ quadrimestre de 2017. Disponível em: www.univali.br/direitoepolitica - ISSN 1980-7791

debatida é se seria esse novo modelo social pautado no consumo e na produção de massa sustentável?

Ao se compreender o nosso atual modelo social se torna fácil compreender a sua insustentabilidade, pois, diante do alto consumo e da produção altamente massificada, a conta do meio ambiente não fecha.

Já que nessa formatação social, em que os indivíduos são julgados pelo que consomem, pelos bens que possuem, pelo local que frequentam, consome-se por um ato individualista sem preocupação nas consequências dessa decisão, é um consumo inconsciente, principalmente por se saber que é a natureza que fornece a matéria-prima para produzir os bens e proporcionar os serviços, quase que na sua totalidade, de forma não renovável ${ }^{40}$.

Por isso as consequências desse modelo social têm despertado a preocupação de inúmeros estudiosos e cientistas, dentre os quais se destaca Serge Latouche. Já no prólogo da sua obra, o autor francês ${ }^{41}$, conhecido mundialmente por ser um assíduo defensor e o mais notório partidarista do decrescimento sustentável ${ }^{42}$, faz diversas reflexões a respeito da posteridade, como quando diz:

¿Y después? Hoy, que hemos agotado la dote patrimonial, ¿debemos continuar complaciéndonos hasta el triste final, y arrastrar lo esencial del resto del mundo al abismo? ¿O bien habría que reconocer que la fiesta ha acabado, limpiar y preparar el lugar para los que vengan a continuación?.

40 EFING, Antônio Carlos; DE RESENDE, Augusto César Leite. Educação para o consumo consciente: um dever do Estado. RDA: Revista de Direito Administrativo, v. 269, p. 197, 2015, p. 211.

${ }^{41}$ LATOUCHE. Serge, Salir de la Sociedad de Consumo. Barcelona: Octaedro, 2014, p. 7-8.

42 O decrescimento é um conceito político-econômico criado em meados da década de setenta do século passado, baseado na obra The Entropy Law and the Economic Process, de Nicholas GeorgescuRoegen. Em suma, a ideia pauta-se na concepção de que o crescimento mundial vivido nos últimos anos, alicerceado pela cultura consumista (hiperconsumista) burguesa, é insustentável pelo simples fato de que os recursos naturais são escassos e limitados. Ver mais em: LATOUCHE, Serge. Pequeno tratado do decrescimento sereno. Tradução de Cláudia Berliner. São Paulo: WMF Martins Fontes, 2001 [2007]. 
HECKTHEUER, Pedro Abib; PIGNANELI, Guilherme da Costa Ferreira; HECKTHEUER, Marcia Abib. O E-Commerce como potencializador da insustentável cultura do consumo na sociedade tecnológica: um desafio sociambiental. Revista Eletrônica Direito e Política, Programa de Pós-Graduação Stricto Sensu em Ciência Jurídica da UNIVALI, Itajaí, v.12, n.3, $3^{\circ}$ quadrimestre de 2017. Disponível em: www.univali.br/direitoepolitica - ISSN 1980-7791

Mais do que propriamente uma crítica ao sistema econômico capitalista, depreende-se de sua obra e do texto acima uma preocupação no sentido de entender necessário que se possa combater os valores ocidentais e modernos que tem no seu cerne a ideia de dominação da natureza, sob pena de deteriorarmos tanto o meio ambiente a ponto de inviabilizar as futuras gerações ${ }^{43}$.

Em realidade, o problema e o questionamento não parece ser, como pretendem em geral os ecologistas, em torno do consumo excessivo da população e a busca de limites a isso, mas sim "o tipo de consumo atual, fundado na ostentação, no desperdício, na alienação mercantil, na obsessão acumuladora, que deve ser questionado." 44

O custo ambiental é ignorado neste modelo social, da economia globalizada (sociedade de consumo), levando a um caminho em que o ecossistema está sendo tão degradado e prejudicado que o dano não mais terá reparação, cabendo ressaltar que "a destruição ambiental não é somente um efeito colateral, mas um elemento essencial da concepção do capitalismo global"45.

A forma atual do capitalismo global, por meio de uma cultura do consumo, em meio a sociedade tecnológica, está se demonstrando insustentável do ponto de vista ecológico, e por isso não é viável a longo prazo, e o destino último do capitalismo global pode ser "a rejeição social, cultural e política, por parte de um grande número de pessoas no mundo inteiro, de um autômato cuja lógica ignora ou desvaloriza a humanidade dessas pessoas"46.

Essa preocupação ambiental não é falaciosa, são dados consolidados, sabe-se que se consome $25 \%$ mais recursos naturais do que a capacidade de renovação da

43 LATOUCHE, Serge. Pequeno tratado do decrescimento sereno. Tradução Claudia Berliner. São Paulo: Editora VWF Martins Fontes, 2009, p. 127-131.

44 LÖWY, Michael. Ecologia e Socialismo. São Paulo: Cortez, 2005, p. 52.

45 CAPRA, Fritjof. As conexões ocultas: ciência para uma vida sustentável. São Paulo: Cultrix, 2005, p.159.

${ }^{46}$ CAPRA, Fritjof. As conexões ocultas: ciência para uma vida sustentável. São Paulo: Cultrix, 2005, p. 159. 
HECKTHEUER, Pedro Abib; PIGNANELI, Guilherme da Costa Ferreira; HECKTHEUER, Marcia Abib. O E-Commerce como potencializador da insustentável cultura do consumo na sociedade tecnológica: um desafio sociambiental. Revista Eletrônica Direito e Política, Programa de Pós-Graduação Stricto Sensu em Ciência Jurídica da UNIVALI, Itajaí, v.12, n.3, $3^{\circ}$ quadrimestre de 2017. Disponível em: www.univali.br/direitoepolitica - ISSN 1980-7791

terra, em se mantendo os padrões de consumo atual, em menos de 50 anos precisaríamos de dois planetas terra para atender nossas necessidades, mas o fato é que o padrão de consumo tem aumentado e está sendo potencializado pelas novas formas de acesso aos produtos, como é o caso do e-commerce, o que está acelerando essa degradação ${ }^{47,48}$.

Viu-se, com isso, que as preocupações dos autores não são exageradas, nem, tampouco, infundadas, portanto, qual seria a alternativa ou mecanismo capaz de segurar toda essa gana por consumir e, consequentemente, buscar a sustentabilidade socioambiental, ou seria a sociedade de consumo um caminho sem volta?

Parece não haver alternativa se não a de adoção, urgente, da prática do consumo consciente, ou seja, "a própria preservação do planeta depende desta nova conduta"49, pois consciente de seu papel, o consumidor terá condições de maximizar os impactos socioambientais positivos e minimizar os negativos, pois ele possui características diferentes daquelas impostas pela sociedade de consumo, quais sejam:

O consumidor consciente não é individualista, não pensa apenas em sua satisfação econômica pessoal, ele também se preocupa com os impactos socioambientais que a produção, distribuição e consumo de bens e serviços provocam na sociedade e, por isso, escolhe produtos cuja produção obedece a critérios sociais e ambientais. Isso é consumo consciente ${ }^{50}$

47 HAILS, Chris et al. Relatório planeta vivo 2006. Gland-Suíça: World Wide Fund for Nature-WWF, Zoological Society of London-ZSL e Global Footprint Network, p. 115-190, 2006, p. 1.

48 EFING, Antônio Carlos; DE RESENDE, Augusto César Leite. Educação para o consumo consciente: um dever do Estado, 2015, p. 210.

49 EFING, Antônio Carlos; DE RESENDE, Augusto César Leite. Educação para o consumo consciente: um dever do Estado, 2015, p. 211.

50 EFING, Antônio Carlos; DE RESENDE, Augusto César Leite. Educação para o consumo consciente: um dever do Estado, 2015, p. 211. 
HECKTHEUER, Pedro Abib; PIGNANELI, Guilherme da Costa Ferreira; HECKTHEUER, Marcia Abib. O E-Commerce como potencializador da insustentável cultura do consumo na sociedade tecnológica: um desafio sociambiental. Revista Eletrônica Direito e Política, Programa de Pós-Graduação Stricto Sensu em Ciência Jurídica da UNIVALI, Itajaí, v.12, n.3, $3^{\circ}$ quadrimestre de 2017. Disponível em: www.univali.br/direitoepolitica - ISSN 1980-7791

Para tanto, é necessário que haja uma mudança significativa no comportamento dos consumidores, e para que isso se efetive, parece ser necessário maior informação sobre essa realidade, ou seja, carece-se de uma educação para o consumo consciente, para tanto, deve haver uma atuação positiva do Estado, por meio de políticas públicas de educação que proporcionem uma conscientização da necessidade de mudança comportamental dos consumidores, pois, como defendem Efing e Resende ${ }^{51}$, "o Estado está constitucionalmente obrigado a promover o direito ao desenvolvimento sustentável".

As respostas para os questionamentos levantados não são assertivas, tampouco unânimes, no entanto, há uma certeza, no sentido de que se não houver a conscientização de que o planeta existe há milhões de anos, por outro lado, os seres humanos chegaram há pouco tempo e são os responsáveis por estar transgredindo, sobremaneira, o equilíbrio da natureza (planeta), de tal maneira que, como já demonstrado, chegará o momento que ele, o planeta, nos irá tirar daqui.

Ou seja, nessa história do planeta, os seres humanos são os que chegaram por último e estão sendo os responsáveis por romper o equilíbrio, a ponto de acabar com a própria vida. É importante ressaltar que o planeta seguirá vivendo, no entanto, a problemática está no fato de que temos que seguir vivendo, também nós, os humanos ${ }^{52}$.

\section{CONSIDERAÇÕES FINAIS}

O consumo, como se observou em um momento inicial, existiu deste as sociedades mais remotas, no entanto, a denominada sociedade de consumo, tem sua origem, em verdade, após diversas mudanças e fatores sociais, bem como históricos, podendo-se destacar o conjunto de novos bens de consumo e de produtos supérfluos, principalmente em função da expansão marítima. Deve-se destacar a

51 EFING, Antônio Carlos; DE RESENDE, Augusto César Leite. Educação para o consumo consciente: um dever do Estado, 2015, p. 216.

52 ZAFFARONI, Eugenio Raúl. La Pachamama y el humano. Buenos Aires: Ediciones Madres de Plaza de Mayo, 2012. 
HECKTHEUER, Pedro Abib; PIGNANELI, Guilherme da Costa Ferreira; HECKTHEUER, Marcia Abib. O E-Commerce como potencializador da insustentável cultura do consumo na sociedade tecnológica: um desafio sociambiental. Revista Eletrônica Direito e Política, Programa de Pós-Graduação Stricto Sensu em Ciência Jurídica da UNIVALI, Itajaí, v.12, n.3, $3^{\circ}$ quadrimestre de 2017. Disponível em: www.univali.br/direitoepolitica - ISSN 1980-7791

opulência econômica que se vivenciou após esse fato, conduzindo para uma nova dimensão cultural, fazendo uma mudança de um consumo eminentemente familiar para o individual.

Tudo isso fez com que o consumo ganhasse espaço na vida das pessoas e não só a fazer parte, mas ter papel-chave, ser um propósito de existir. Por outro lado, viu-se que também a sociedade contemporânea é analisada sob um viés da informação, da comunicação, do conhecimento, principalmente em virtude do desenvolvimento fugaz das tecnologias de informação e comunicação (sociedade tecnológica).

Em verdade, o que se pôde verificar é que a sociedade de consumo e a sociedade da informação e da tecnologia são duas faces da mesma moeda. Isso porque, as mídias veiculadoras de informação, são as mesmas que retroalimentam esse ciclo vicioso do desejo pelo novo.

E foi a partir dessa revolução tecnológica, que teve como centro as tecnologias de informação e comunicação, que se teve uma reformulação geral da sociedade, incluindo como centrais os computadores e celulares com acesso a internet, passando a interligar dezena de milhões de pessoas em todo o mundo, dando acesso irrestrito às informações.

Dessa forma, pode-se dizer que a sociedade do consumo se caracteriza por um consumo em massa, já, com o advento da internet esse consumo se intensificou ainda mais, e passou a ser caracterizado como sendo um consumo "pós-massivo". E essa mudança se deu, exclusivamente, pela mudança do meio de acesso aos produtos e a forma pela qual se concretiza essa relação, ou seja, pelo e-commerce.

Em que pese todas as benesses e facilidades do comércio eletrônico, tais como custo baixo, comodidade, possibilidade de comparar os preços rapidamente, esse fenômeno precisa ser estudado com cautela, porquanto, ao facilitar e garantir mais segurança ao consumidor, potencializa, ainda mais, o ciclo vicioso do consumo.

Diversos autores apontam preocupação com relação a essa cultura do consumo, compreendendo que o ponto chave de discussão não está apenas no ponto de 
HECKTHEUER, Pedro Abib; PIGNANELI, Guilherme da Costa Ferreira; HECKTHEUER, Marcia Abib. O E-Commerce como potencializador da insustentável cultura do consumo na sociedade tecnológica: um desafio sociambiental. Revista Eletrônica Direito e Política, Programa de Pós-Graduação Stricto Sensu em Ciência Jurídica da UNIVALI, Itajaí, v.12, n.3, $3^{\circ}$ quadrimestre de 2017. Disponível em: www.univali.br/direitoepolitica - ISSN 1980-7791

haver um consumo excessivo da população e em buscar limites a isso, mas está no tipo de consumo, que se funda na ostentação, no desperdício, na alienação mercantil, na obsessão acumuladora.

O problema de pesquisa, portanto, foi respondido no sentido de confirmar a hipótese levantada, posto que se pôde compreender que o advento da internet e das diversas tecnologias de comunicação e informação, com ênfase no ecommerce, viabilizou e facilitou o consumismo.

Em verdade, a cultura do consumo, ou o fetiche pelo consumo não é característico do e-commerce, é anterior, no entanto o que era massivo se tornou pósmassificado, com o comércio digital, não restando dúvidas de que esse incentivo ao consumismo, dado pelas facilidades do e-commerce, acentuaram sobremaneira a insustentabilidade desse modelo de sociedade.

Dessa forma, pôde-se chegar ao entendimento de que se não houver a conscientização no tocante ao consumo, bem como com relação aos prejuízos que essa cultura de consumo traz ao meio ambiente, chegar-se-á ao momento em que o planeta o planeta, nos irá tirar daqui.

\section{REFERÊNCIAS DAS FONTES CITADAS}

ALBERTIN, Alberto L. Comércio eletro ^nico: modelo, aspectos e contribuições de sua aplicação. São Paulo: ATLAS, 2002.

BARBOSA, Lívia. Sociedade de Consumo. Rio de Janeiro: Jorge Zahar Editora, 2004.

BAUMAN, Zygmunt. Modernidade Liquida. Rio de Janeiro: Editora Zahar, 2001. BAUMAN, Zygmunt. Vida para o consumo. Rio de Janeiro: Editora Zahar, 2008. BAUMAN, Zygmunt. Vida para o consumo. Traducción de Mirta Rosenberg y Jaime. Arramrlde. Madrid: Fundo de Cultura Econômica, 2012.

BECK, Ulrich. A Critical Introduction to the Risk Society. London: Pluto Press, 2004.

CAPRA, Fritjof. As conexões ocultas: ciência para uma vida sustentável. São Paulo: Cultrix, 2005. 
HECKTHEUER, Pedro Abib; PIGNANELI, Guilherme da Costa Ferreira; HECKTHEUER, Marcia Abib. O E-Commerce como potencializador da insustentável cultura do consumo na sociedade tecnológica: um desafio sociambiental. Revista Eletrônica Direito e Política, Programa de Pós-Graduação Stricto Sensu em Ciência Jurídica da UNIVALI, Itajaí, v.12, n.3, $3^{\circ}$ quadrimestre de 2017. Disponível em: www.univali.br/direitoepolitica - ISSN 1980-7791

CASTELLS, Manuel. A Galáxia Internet: reflexões sobre a Internet, negócios e a sociedade. Zahar, 2003.

COPPEL, Jonathan. E-Commerce: Impacts and Policy Challenges. OECD Economics Department Working Papers. No. 252, Junho de 2000. Disponível em: http://www.oecd-ilibrary.org/economics/e-commerce_801315684632. Acessado em: 24 de setembro de 2017.

CORREA, Fabiano Simoes. Um estudo sobre as representações utilizadas por professores e alunos para significar o uso da internet. Dissertação de Mestrado apresentada à Faculdade de Filosofia, Ciencias e Letras de Ribeirão Preto da USP, 2013. Disponível em: < file://C:/Users/Guilherme/Downloads/Fabiano Correa Mestrado.pdf >, acesso 14 de ago. 2017.

EFING, Antônio Carlos; DE RESENDE, Augusto César Leite. Educação para o consumo consciente: um dever do Estado. RDA: Revista de Direito Administrativo, v. 269, p. 197, 2015.

FIGUEIREDO, Márcio, FIGUEIREDO, Cristiane e MOREIRA, Halbert. Comércio eletrônico e o direito do consumidor no brasil, 2015. Disponível em: < http://www.unipacto.com.br/revista2/arquivos pdf revista/revista2015/8.pdf >, acesso 14 de ago. 2017.

FREITAS, C. O. A.. A Vulnerabilidade do Consumidor e a Exposição Pública na Internet. In: Aires José Rover, Fernando Galindo. (Org.). III Encontro de Internacionalização do CONPEDI / Universidad Complutense de Madrid. 1ed.Madrid: Ediciones Laborum, 2015, v. 9, p. 76-101.

GEROGE, Eric, Da "sociedade da informação" à "sociedade 2.0": o retorno dos discursos "míticos" sobre o papel das TICs nas sociedades. Líbero São Paulo - v. 14, n. 27, p. 45-54, jun. de 2011.

GONÇALVES, Alex Silva; SCHMIDT, João Pedro. Impactos do consumismo: ação estatal e participação comunitária. Seminário Nacional Demandas Sociais e Políticas Públicas na Sociedade Contemporânea, 2015.

GONÇALVES, Sérgio Campos. Cultura e Sociedade de Consumo: um olhar em retrospecto. InRevista - Nucleo de Produção Cientifica em ComunicaçãoUNAERP, Ribeirão Preto, v. 5, 2008.

HAILS, Chris et al. Relatório planeta vivo 2006. Gland-Suíça: World Wide Fund for Nature-WWF, Zoological Society of London-ZSL e Global Footprint Network, p. 115-190, 2006.

JENKINS, Henry. Convergence culture: Where old and new media collide. NYU press, 2006.

LATOUCHE, Serge. Pequeno tratado do decrescimento sereno. Tradução Claudia Berliner. São Paulo: Editora VWF Martins Fontes, 2009 
HECKTHEUER, Pedro Abib; PIGNANELI, Guilherme da Costa Ferreira; HECKTHEUER, Marcia Abib. O E-Commerce como potencializador da insustentável cultura do consumo na sociedade tecnológica: um desafio sociambiental. Revista Eletrônica Direito e Política, Programa de Pós-Graduação Stricto Sensu em Ciência Jurídica da UNIVALI, Itajaí, v.12, n.3, $3^{\circ}$ quadrimestre de 2017. Disponível em: www.univali.br/direitoepolitica - ISSN 1980-7791

LATOUCHE. Serge, Salir de la Sociedad de Consumo. Barcelona: Octaedro, 2014.

LEMOS, André. e Lévy, Pierre, O Futuro da internet: em direção a uma ciberdemocracia. São Paulo: Paulus, 2010.

LIPOVETSKY, Gilles. O império do efêmero: a moda e seu destino nas sociedades modernas. Tradução: Maria Lucia Machado. São Paulo: Companhia das Letras, 2009.

LORENZETTI, Ricardo Luis, Comércio Eletrônico: Tradução de Fabiano Menk; com notas de Cláudia Lima Marques. São Paulo: Revistas dos Tribunais, 2004.

LÖWY, Michael. Ecologia e Socialismo. São Paulo: Cortez, 2005.

MACHLUP, Fritz, The Production and Distribution of Knowledge in the United States. Review of Economic Studies, 1935.

NASCIMENTO. Marina Correa de Sá, A moda de o grande gatsby: uma análise do consumo na pósmodernidade. Trabalho apresentado à Faculdade de Tecnologia e Ciências Sociais Aplicadas, 2013. Disponível em: < http://repositorio.uniceub.br/bitstream/235/5016/1/21054702.pdf > acesso 14 de ago. 2017.

PAESANI, Liliana Minardi, Direito e Internet Liberdade de Informação, Privacidade e Responsabilidade Civil. 5. ed, : São Paulo: Atlas, 2012.

SMITH, Rob, SPEAKER, Mark. O Mais Completo Guia Sobre E-COMMERCE. Tradução Bazán Tecnologia e Lingüística. São Paulo: Futura, 2000.

SVENDSEN, Lars. Moda: uma filosofia. Tradução: Maria Luiza X. de A. Borges. Rio de Janeiro : Zahar, 2010.

WEBSHOPPERS, 2017. Disponível em: < http://www.ebit.com.br/webshoppers > acesso 14 de ago. 2017.

ZAFFARONI, Eugenio Raúl. La Pachamama y el humano. Buenos Aires: Ediciones Madres de Plaza de Mayo, 2012.

Submetido em: outubro de 2017

Aprovado em: dezembro de 2017 